\title{
THE TEXTURE OF A SLATE FROM NANTLLE, CAERNARVON, NORTH WALES
}

\author{
GERHARD OERTEL and PREM P. PHAKEY $\dagger$ \\ Department of Geology, University of California \\ Los Angeles, California
}

(Received December 13, 1971)

\begin{abstract}
A specimen of Cambrian slate from the slate belt in North Wales has been thinned by the ion bombardment technique to produce an ultrathin section with the specimen plane normal to the cleavage plane. This specimen has been investigated with the electron microscope by electron transmission. Selected area diffraction patterns allow identification of individual sheet silicate grains. The pole figures of the basal planes of two sheet silicate minerals, muscovite and chlorite, have been measured with an X-ray pole-figure goniometer and both show an elongated maximum normal to the slaty cleavage, with orthorhombic symmetry. While the preferred orientation could be the result of mechanical rotation of rigid flakes in a deforming matrix, the texture (the overall pattern due to the shapes and sizes of grains and their angular relations to each other) can only be explained if considerable recrystallization is assumed. It is tentatively proposed that local dissolution at points of stress-concentration with simultaneous redeposition of the dissolved material in less stressed regions may have allowed closely packed grains to act as if they were mechanically rotating rigid flakes, yet to accommodate their shapes enough to prevent interlocking.
\end{abstract}

\section{INTRODUCTION}

Slaty cleavage is a penetrative fissility of finegrained, phyllosilicate-rich rocks which is due to a fairly homogeneous preferred orientation of the phyllosilicate grains in a plane generally different from the bedding plane. Phyllosilicate minerals (with sheet-silicate structure) such as muscovite, biotite, chlorite or kaolinite consist of strongly bonded sheets of silicate, more loosely held together in stacks. The symmetry of the sheets themselves is hexagonal, but they can only be stacked with an offset between any two neighboring sheets. The stacking can be random, but more frequently it is systematic according to one of several stacking laws. This gives rise to polytypes for most phyllosilicates (polytypes are polymorphs due to variations in stacking). Local breaks of the stacking sequence within a crystal are frequent and are called stacking faults.

Slates have been regarded as either sedimentary or mildly metamorphic rocks or as a class of rocks on the boundary between these two. Slaty cleavage has been taken to be due to recrystallization under

$\uparrow$ Present address: Department of Physics, University of California, Berkeley. Permanent address: Department of Physics, Monash University, Melbourne, Australia. stress which favors nucleation or growth of grains with basal planes orthogonal to the principal direction of maximum compression. It has also been explained by the simple mechanical rotation of rigid, tabular particles as would occur if such grains were embedded in a matrix that behaves as a viscous fluid or as a plastic solid undergoing strain. In that case the flakes must end up most frequently with their long dimensions (generally in the crystallographic basal plane) orthogonal to the direction of greatest shortening. The causative strain may be thought of as preserving the original volume or as involving a loss of volume due to loss of pore water. ${ }^{1}$ The history of thoughts on the origin of slaty cleavage goes back well over a hundred years, and much of it is covered by a review of the subject by Wilson ${ }^{2}$.

One of the authors recently had occasion ${ }^{3}$ to emphasize the near-sufficiency of the simple, mechanical rotation of grains to explain the observed fabric of one slate. Now we present evidence indicating the importance of recrystallization in producing the observed texture in another slate with a fabric much like that of the first. (We are using the words texture and fabric in the sense usual among geologists. ${ }^{4}$ Texture, to them, is the overall pattern of the shapes and sizes of the grains in a crystalline substance and of the angular re- 
lationships between neighboring grains. Fabric is the texture, in this sense, combined with the preferred orientation, the frequency with which grains in a domain have various crystallographic orientations. Thus, our term "fabric" is a synonym of the metallurgists' term "texture", but there is no counterpart for our more narrowly defined term "texture" in the metallurgists' vocabulary). Details of the texture of slates have gone undescribed so far, mostly because of the fine grain of these rocks, making optical observation unsatisfactory for a complete inspection of fabric features.

Use of the ion-bombardment technique of thinning rock samples ${ }^{5}$ now makes it possible to observe slates and other fine-grained phyllosilicate rocks with the electron microscope by the transmission method, including the possibility of examining selected area diffraction patterns. What makes the method especially useful is the ability to prepare ultrathin sections orthogonal to the slaty cleavage or sedimentary bedding. This allows observation of phyllosilicate grains with their basal planes at right angles to the specimen plane, so that the diagnostic basal $d$-spacings of the phyllosilicate polymorphs may be measured directly.

\section{OBSERVATIONS}

Oriented sample W22 is a purple slate taken from one of the quarries of Dorothea Slate Quarry Co. near Nantlle, Caernarvon, North Wales, at a point within $50 \mathrm{~m}$ from National Grid coordinates 249850,353200 (Figure 1). It is part of the approximately $250 \mathrm{~m}$ thick Purple Slate Group which was defined by Morris and Fearnsides ${ }^{6}$ and by them assigned on lithological grounds to near the base of the Middle Cambrian. The rock consists of muscovite and chlorite, both with strong preferred orientation, quartz and some albite as detrital grains and as recrystallized grains in the interstices, and a fine dusting of hematite $\left(\mathrm{Fe}_{2} \mathrm{O}_{3}\right)$, which gives the rock its color. A few, widely spaced ellipsoidal "reduction spots" are found in the sample. In these spots hematite is absent and the rock in them is light apple-green, due to chlorite interspersed in colorless and white minerals.

Bedding in the sample is defined by widely spaced, thin, slightly silty to sandy layers and strikes north with a $35^{\circ}$ dip to the east. Slaty cleavage strikes $40^{\circ}$ and dips $87^{\circ}$ to the southeast. A lineation in the plane of cleavage is due to slight undulations of the cleavage surfaces. It pitches $85^{\circ}$ to the southwest in the cleavage plane and thus plunges $84^{\circ}$ southward.

The preferred orientation of the two phyllosilicate minerals in the slate were measured with an X-ray goniometer by the method of Baker et al. ${ }^{7}$, and Oertel $^{3}$. They are almost identical; the basal $(00 l)$ planes of both muscovite and chlorite lie preferentially in the plane of cleavage with variance of the pole of the basal plane much greater in the plane normal to the lineation than in the plane

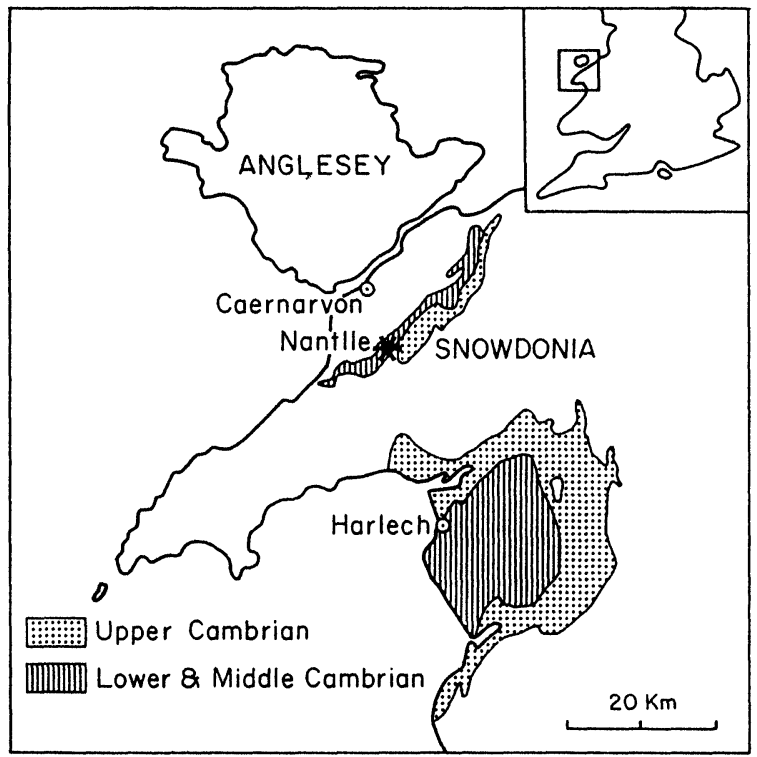

FIGURE 1 Sample location at Nantlle in the Lower and Middle Cambrian slate belt of North Wales.

normal to the cleavage but containing the lineation (Figure 2). Orientation of the muscovite basal plane parallel to cleavage is 16 times more frequent than it would be in a rock with randomly distributed muscovite. The frequency of basal planes normal to cleavage is indistinguishable from zero. Crystallographic directions in the basal plane of muscovite are oriented at random in the plane of slaty cleavage.

An ordinary, approximately $15 \mu \mathrm{m}$ thick thinsection and an ultrathin section were made so that the observer looks down nearly vertically along the lineation. This insures that the maximum number of phyllosilicate grains have their basal planes normal to the plane of the section.

Figure 3 is a medium power view with the petrographic microscope. Polarizers are crossed at $45^{\circ}$ to the plane of foliation. Roundish to oblong 


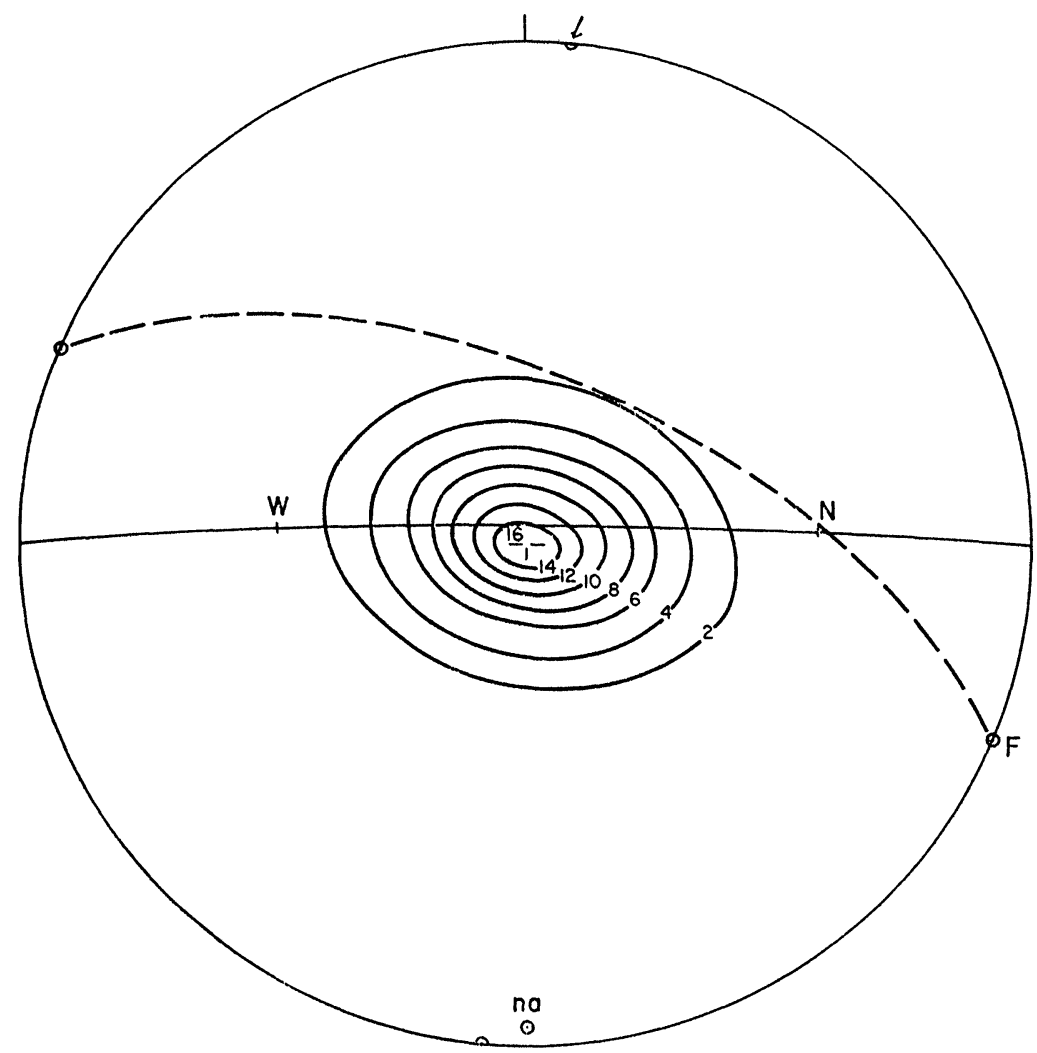

FIGURE 2 Preferred orientation of muscovite. Lower hemisphere of equal-area projection. Contours on multiples of random intensity. Thin line-trace of the horizontal plane, marked $N$ and $W$ at the north and west azimuths. na-nadir. Dashed line-trace of bedding plane. F-fold axis defined by the intersection of the bedding plane with the plane of slaty cleavage. $l$-lineation.

pods of about $50 \mu \mathrm{m}$ diameter consist mostly of relatively large chlorite grains with the traces of their basal planes at all angles, and sometimes at right angles to that of the foliation. The pods are surrounded by a felted-looking groundmass of strongly oriented muscovite and chlorite with interstitial grains of quartz and sometimes of albite. A few round grains of quartz are up to $25 \mu \mathrm{m}$ in diameter and are not interstitial but rather give the impression of being essentially unaltered original sedimentary grains. These grains, like the chlorite pods, are imbedded in the groundmass so that the plane of foliation is locally deflected around them.

There are somewhat diffuse bands or lenses of groundmass in which the individual grains are either predominantly in extinction or not. Most of these bands form traces parallel to the trace of the plane of foliation, but some of them form angles of up to about $30^{\circ}$ with this trace. The overall im- pression of very fine grain in this photograph is partly misleading and is an effect of overlap of grains due to the thickness of the thin-section.

Figure 4 shows part of the same thin-section more highly magnified. What is shown would all be part of the groundmass of Figure 3. Muscovite and chlorite grains occur in two distinct size classes. The larger grains are about $20 \mu \mathrm{m}$ long parallel to the basal plane and about $4 \mu \mathrm{m}$ thick, and are in a finer-grained groundmass of the same minerals. The trace of the foliation of this groundmass can be seen to accomodate itself to the outlines of the larger grains. Hematite occurs in grains mostly less than a micron in diameter (recognizable by its color but not on a photograph). The largest hematite grains are idiomorphic (that is, bounded by low-index crystal faces). If included in phyllosilicates they are frequently arranged in distinct layers, following the basal plane of the host 


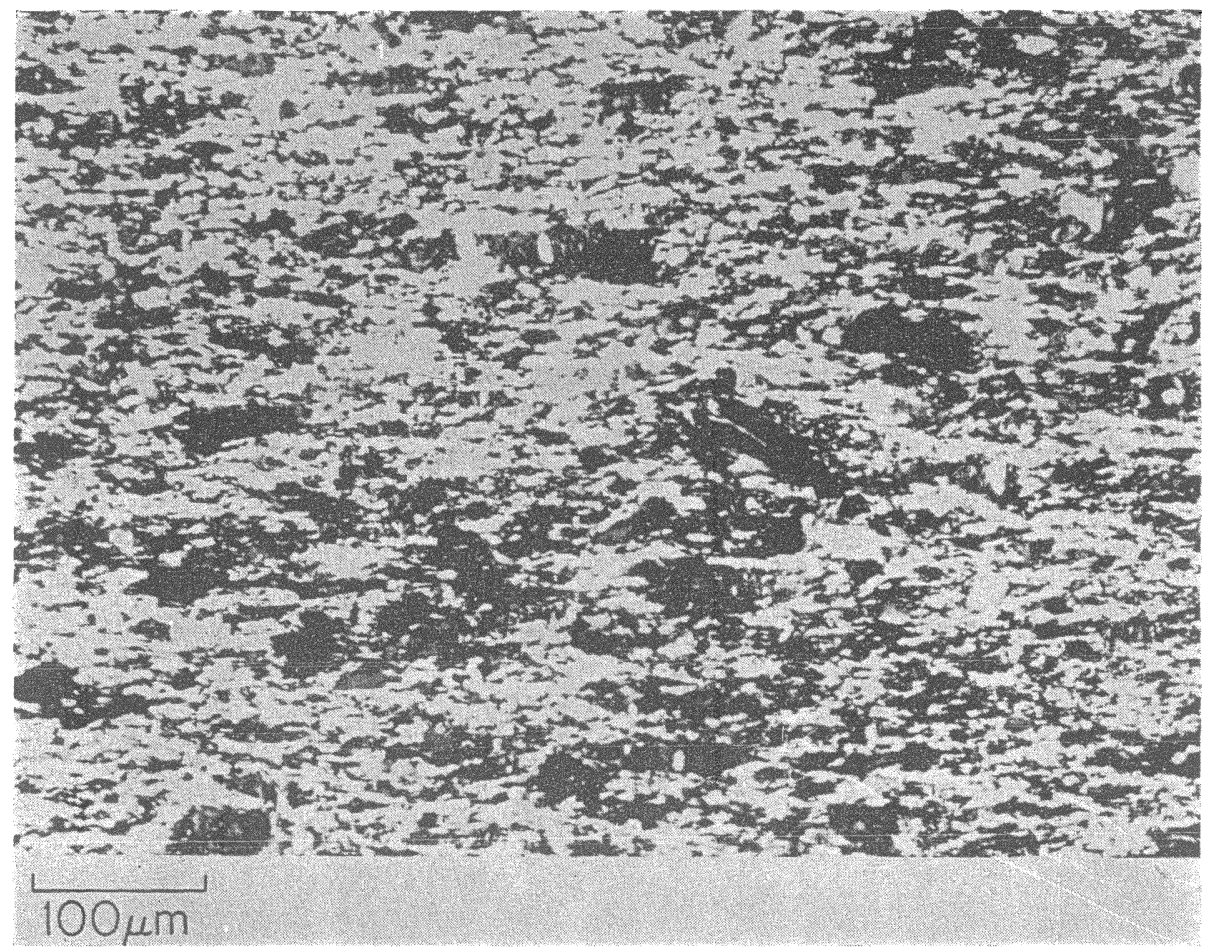

FIGURE 3 Photomicrograph. View parallel to lineation, trace of slaty cleavage east-west, polarizers crossed at $45^{\circ}$ from edges.

crystals. Quartz fills irregularly shaped spaces between the muscovites and chlorites. Some of the quartz grains are filled with randomly distributed inclusions of hematite, some are clear.

Were it not for the scale, the texture in the composite electron micrograph, Figure 5 , could be called schistose. Hypidiomorphic (that is, bounded in part by low-index crystal faces) grains of phyllosilicate (muscovite and chlorite are indistinguishable in the transmission electron microscope except for their diffraction patterns) form sheaves with small angles between the basal planes of neighboring grains. The average orientation of basal planes of these sheaves can be seen to wrap somewhat imperfectly around the outline of a "large" ( $\sim 3 \mu \mathrm{m}$ thick) muscovite grain of unknown length, marked $p_{1}$. Another large grain, $p_{2}$, has less well-defined boundaries. Cleavage cracks (marked $c$ on Figure 5 and probably formed during specimen preparation) penetrate grain $p_{1}$ and one of them continues as a crack following a grain boundary.

The phyllosilicate grains in Figure 6 are comparable in size to the "large" grains discussed in the preceding section. The central grain $p$ is muscovite as determined by its selected area electron diffraction pattern. The nearly black grain, $h$, is probably hematite. A grain of quartz (marked $q$ ) abuts against a basal plane of grain $p$. The mottled appearance of the phyllosilicate grains may be an expression of a fine-scale domain structure.

Figure 7 shows a number of phyllosilicate flakes (labelled $p_{1}, p_{2}$, etc.) and quartz grains (labelled $q_{1}$, $q_{2}$, etc.). The selected area diffraction pattern was taken from the encircled area. The diffraction pattern shows three sets of rows of spots passing through the center. These are labelled $p_{1}, p_{2}$, and $p_{3}$ respectively, and belong to the phyllosilicate flakes in the micrograph with the same labels. From the $d$-spacing of $10 \AA$ it is probable that all three grains are muscovite with basal planes normal to the plane of the specimen, and all boundaries between the phyllosilicate flakes and the quartz grain are vertical. The cross-grid pattern of spots in the selected area diffraction pattern belongs to the quartz grain $q_{1}$. The $(3 \overline{1} \overline{2} 0)$ plane of quartz makes a vertical boundary with the (001) plane of $p_{1}$. Another plane of quartz, (1102), makes a similar boundary with the (001) plane of $p_{2}$. The 


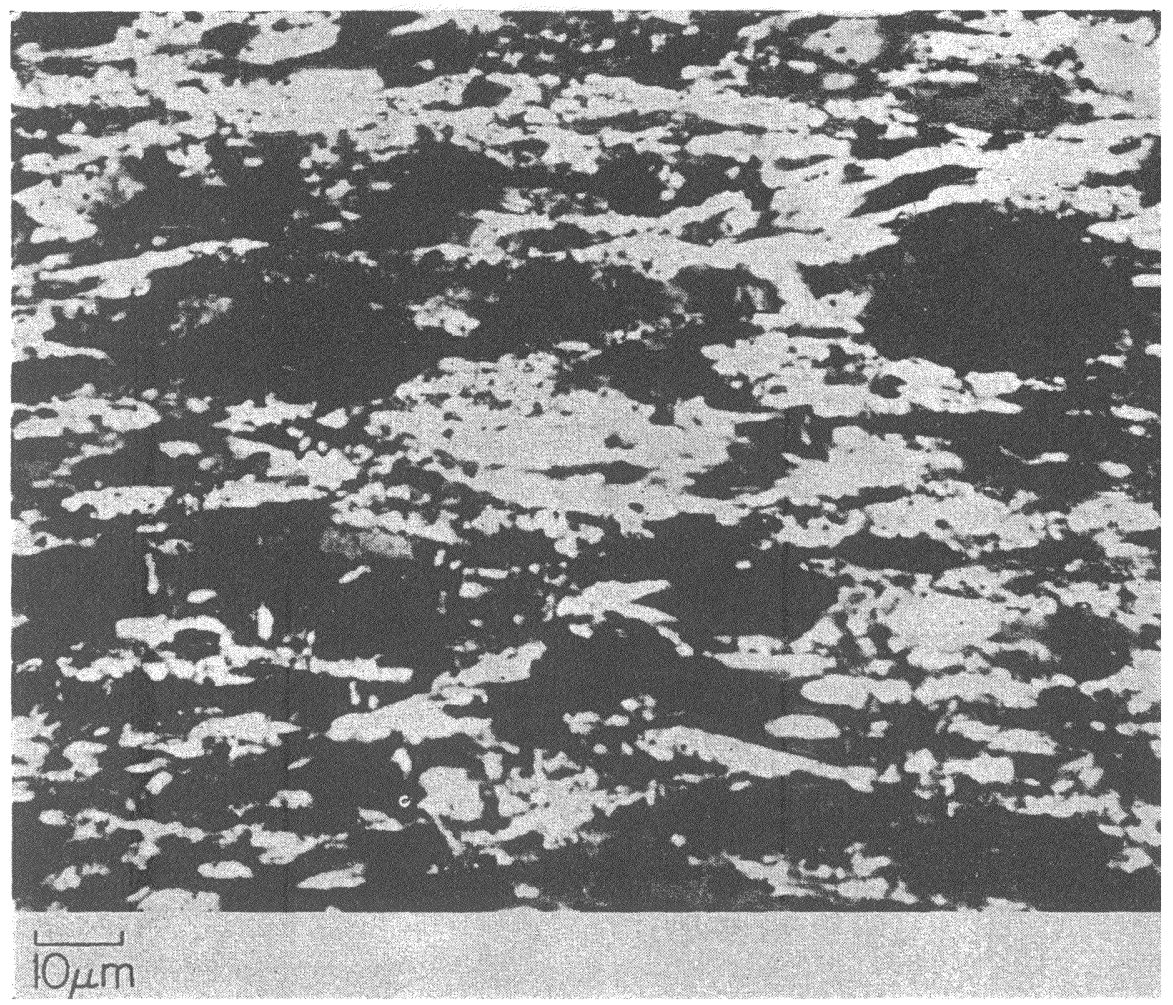

FIGURE 4 Photomicrograph. View parallel to lineation, trace of slaty cleavage east-west, polarizers crossed at $45^{\circ}$ from edges.

quartz grain $q_{2}$ is thus wedged between $p_{2}$ and $p_{3}$ with boundaries that are crystallographic planes for all three grains.

Figure 8 is highly magnified, with none of the grains thicker normal to the base than one micron. The grain, $q$, is quartz, bounded on the sides by the basal planes of phyllosilicate grains, $p_{1}$ and $p_{2}$. Very fine striations in these two grains are probably stacking faults parallel to the base. Thickness fringes are displaced along these faults, especially clearly in grain $p_{2}$. A selected area diffraction pattern of grains $p_{3}$ and $p_{4}$ shows them to have $10 \AA$ spacing (probably 002 of muscovite) and to have basal planes again normal to the specimen plane.

In none of the electron micrographs from this sample, those illustrated and a number of others, have many dislocations been observed in grains of phyllosilicates or quartz. From observations on other, similarly prepared, samples we know that dislocations would have been discovered had they been present.

\section{DISCUSSION AND CONCLUSIONS}

The observed preferred orientation of phyllosilicate (001) planes in the slate could have been brought about, either in a single act or in a sequence of events, ${ }^{8}$ by the passive rotation of rigid particles in an easily deformed matrix, possibly with loss of volume by dewatering. The submicroscopic structure of the rock shows, however, that this simple explanation is inadequate. Over large domains the rock consists of a spacefilling aggregate of phyllosilicate grains, with no interstitial material that could have played the role of a matrix. Quartz either exists as large grains, surrounded by a matrix of micaceous grains, or it fills interstitial spaces between phyllosilicate individuals. Thus, if the phyllosilicates were mechanically rotated to their present orientation, portions of them must have been able to dissolve at contact points and then to reappear between these points. Without this ability, grains should have interlocked long before 


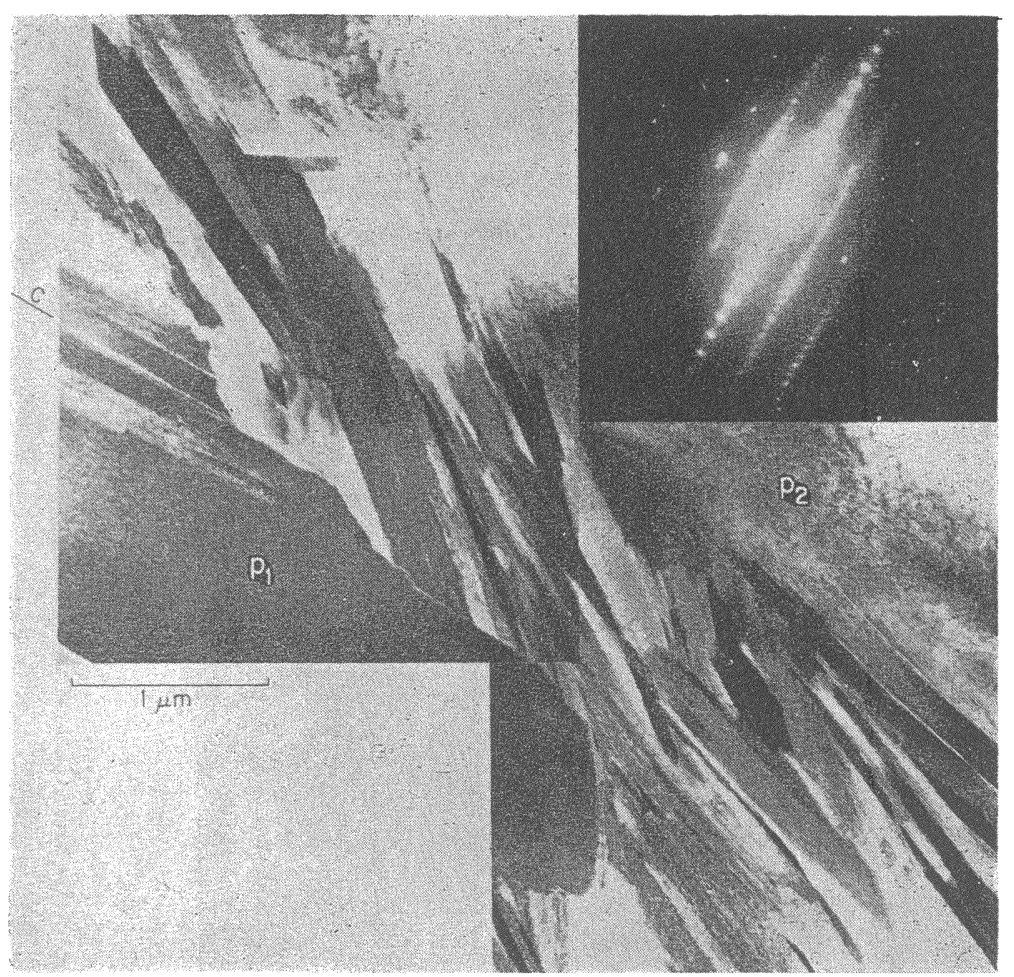

FIGURE 5 Composite electron micrograph. View parallel to lineation. trace of slaty cleavage approximately northwest-southeast. $p_{1}, p_{2}-$ phyllosilicate grains, $p_{1}$ probably muscovite. Insert-selected area diffraction pattern from grain $p_{1}$, taken outside the field of this composite; $d$-spacing, $\approx 10 \AA$, characteristic of (002) of $2 \mathrm{M}$ muscovite.

FIGURE 6 Electron micrograph. View parallel to lineation, trace of slaty cleavage approximately northwest-southeast. $q$-quartz. $p$-phyllosilicate, probably muscovite. $h$-probably hematite. Insert - selected area diffraction pattern of grain $p ; d$-spacing, $\approx 10 \AA$, characteristic of $(002)$ of $2 \mathrm{M}$ muscovite.

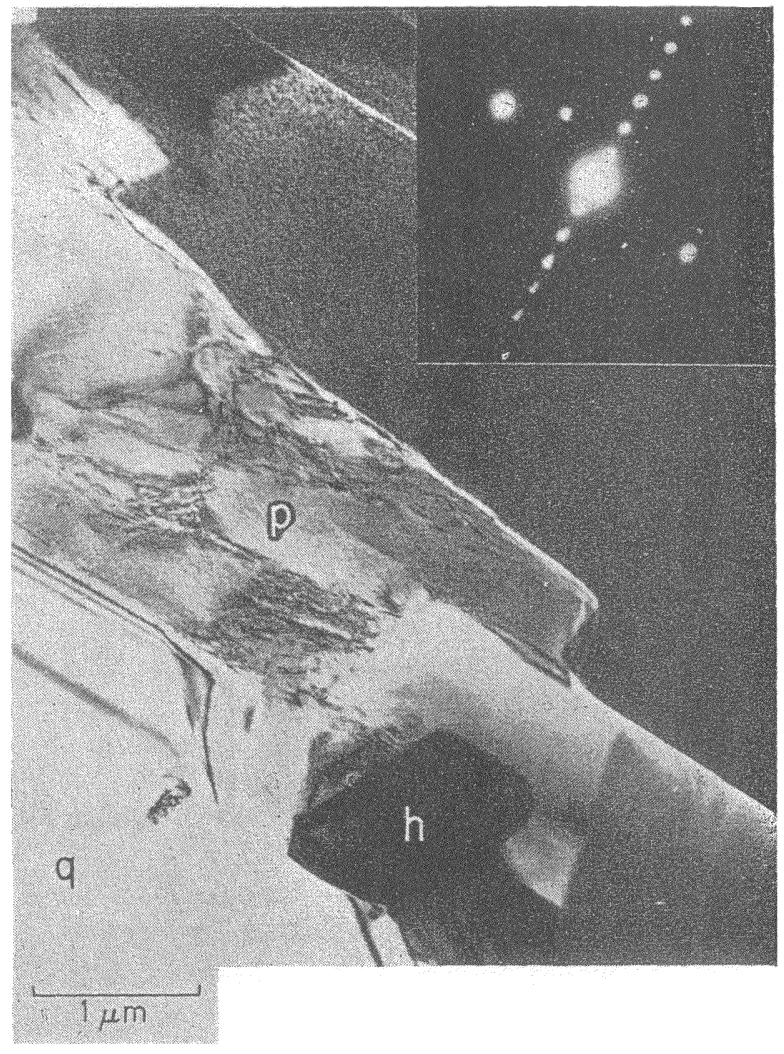


FIGURE 7 Composite electron micrograph. View parallel to lineation, trace of slaty cleavage approximately northwest-southeast. $p_{1}, p_{2}, p_{3}$ phyllosilicate grains. $q_{1}, q_{2}, q_{3}$-quartz grains. Insert-selected area diffraction pattern from encircled area. Indexed spots from quartz $q_{1}$. Rows of regularly spaced spots $p_{1}, p_{2}, p_{3}$ from grains so labelled on micrograph; $d$-spacing, $\approx 10 \AA$, characteristic of $2 \mathrm{M}$ muscovite.
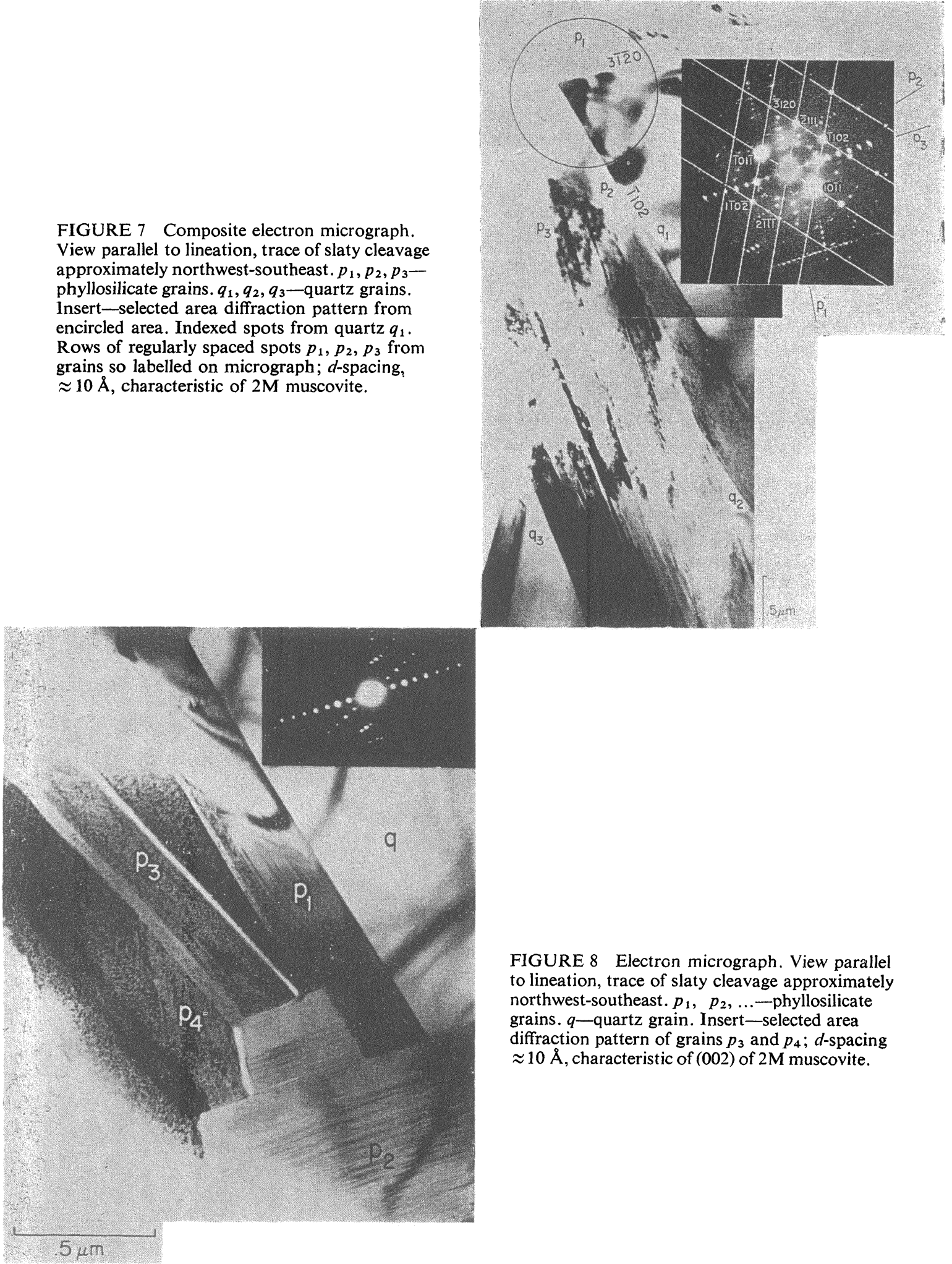

FIGURE 8 Electron micrograph. View parallel to lineation, trace of slaty cleavage approximately northwest-southeast. $p_{1}, p_{2}, \ldots$-phyllosilicate grains. $q$-quartz grain. Insert-selected area diffraction pattern of grains $p_{3}$ and $p_{4} ; d$-spacing $\approx 10 \AA$, characteristic of $(002)$ of $2 \mathrm{M}$ muscovite. 
they could be squeezed into the almost spacefilling arrangement they now form. The mutual accommodation may have occurred by local dissolution at points of stress-concentration with simultaneous redeposition of the dissolved material in stress-shadow regions on the surfaces of existing grains. ${ }^{9}$ In this fashion many "individual" grains may have persisted through a history of passive rotation, and yet been able to move past and "through" each other without fracture or deformation. The framework of grains surrounding each individual grain may be understood to play the role of a plastic matrix, allowing the grain to align its basal plane progressively with the plane of the two relatively most extensile (or least compressive) principal directions of strain as if it were a rigid platelet. This might occur if the grains adjusted the details of their marginal configurations, by solution-redeposition or solid diffusion, to the space available, while retaining their tabular shape. Thus the grain-boundary regions might be sufficiently mobile or deformable to play the role of a fluid matrix. Each grain would generally remain tabular throughout this process.

The texture now observed in the rock is one of a well-annealed, recrystallized material, with grainboundaries formed by far most frequently by the basal plane of one of the two neighboring grains if they are both phyllosilicates. Interstitial quartz is bounded almost invariably by basal planes of phyllosilicates and, in one instance, these same boundaries might also be crystallographic planes of quartz. The interface, however, does not appear to be one due to epitaxy. Generally, the grains and grain boundaries are undeformed and presently stress-free.

Except for the grain size, the texture of this slate is that of a schist, and, by most criteria, one should call it a metamorphic rock. The presence of all critical minerals, if not necessarily fully reconstituted from other phases during the petrogenesis of this rock then at least strongly recrystallized, would make this slate a member of the quartzalbite-muscovite-chlorite metamorphic subfacies according to Turner and Verhoogen ${ }^{10}$.

\section{ACKNOWLEDGMENTS}

This work was supported by National Science Foundation Grant GA 26027 . Thin sections were made by J. deGrosse, the manuscript was typed by J. Schachter, and drafting was by J. Guenther and J. Martinez. J. M. Christie made the optical photomicrographs and read and improved the manuscript. We are grateful for these contributions. We are also indebted to A. J. Ardell for arranging for the use of the JEM 120 electron microscope of the Materials Department, School of Engineering, UCLA.

\section{REFERENCES}

1. J. C. Maxwell, in Petrologic Studies: A volume in honor of A. F. Buddington. (Geological Society of America, New York, 1962), pp. 281-311.

2. G. Wilson, Geol. Assoc. Proc. 57, 263 (1946).

3. G. Oertel, Geol. Soc. Amer. Bull. 81, 1173 (1970).

4. F. J. Turner and L. E. Weiss, Structural Analysis of Metamorphic Tectonites (McGraw-Hill, New York, 1963).

5. P. P. Phakey, C. D. Curtis, and G. Oertel, Clay and Clay Minerals, in press.

6. T. O. Morris and W. G. Fearnsides, Quart.J. Geol. Soc. London 82, 250 (1926).

7. D. W. Baker, H. R. Wenk, and J. M. Christie, J. Geology 77, 144 (1969).

8. B. D. T. Lynas, Geol. Mag. 107, 505 (1970).

9. E. Riecke, Göttinger Nachrichten 4, 278 (1894), as quoted by F. Becke, Congr. Géol. Intern. Wien (1903), pp. 553-570.

10. F. J. Turner and J. Verhoogen, Igneous and Metamorphic Petrology. (McGraw-Hill, New York, 1960), 2nd ed., p. 535. 